\title{
Experimental mapping of the canine KCNJ2 and KCNJ12 gene structures and functional analysis of the canine $\mathrm{K}_{\mathrm{IR}} 2.2$ ion channel
}

\author{
Marien J. C. Houtman, Hiroki Takanari, Bart G. J. M. Kok, Margot van Eck, Denise R. Montagne, \\ Marc A. Vos, Teun P. de Boer and Marcel A. G. van der Heyden*
}

Division Heart and Lungs, Department of Medical Physiology, University Medical Center Utrecht, Utrecht, Netherlands

\section{Edited by:}

Tobias Opthof, Academic Medical

Center, Netherlands

Reviewed by:

Luigi Venetucci, University of

Manchester, UK

Krzysztof R. Grzeda, Boston College, USA

Roos Marsman, Academic Medical Center, Netherlands

\section{*Correspondence.}

Marcel A. G. van der Heyden, Division Heart and Lungs, Department of Medical Physiology, University Medical Center Utrecht, Yalelaan 50, 3584 CM Utrecht, Netherlands. e-mail:m.a.g.vanderheyden@ umcutrecht.nl

\begin{abstract}
For many model organisms traditionally in use for cardiac electrophysiological studies, characterization of ion channel genes is lacking. We focused here on two genes encoding the inward rectifier current, $K C N J 2$ and $K C N J 12$, in the dog heart. A combination of RT-PCR, $5^{\prime}$ RACE, and $3^{\prime}-$ RACE demonstrated the status of $K C N J 2$ as a two exon gene. The complete open reading frame (ORF) was located on the second exon. One transcription initiation site was mapped. Four differential transcription termination sites were found downstream of two consensus polyadenylation signals. The canine KCNJ12 gene was found to consist of three exons, with its ORF located on the third exon. One transcription initiation and one termination site were found. No alternative splicing was observed in right ventricle or brain cortex. The gene structure of canine KCNJ2 and KCNJ12 was conserved amongst other vertebrates, while current GenBank gene annotation was determined as incomplete. In silico translation of $K C N 12$ revealed a non-conserved glycine rich stretch located near the carboxy-terminus of the $\mathrm{K}_{\mathrm{IR}} 2.2$ protein. However, no differences were observed when comparing dog with human $\mathrm{K}_{\mathrm{IR}} 2.2$ protein upon ectopic expression in COS-7 or HEK293 cells with respect to subcellular localization or electrophysiological properties.
\end{abstract}

\section{INTRODUCTION}

In the mammalian heart, the resting membrane potential of cardiomyocytes is set and stabilized by the inward rectifier potassium current $\left(I_{\mathrm{K} 1}\right.$; Dhamoon and Jalife, 2005). In addition, $I_{\mathrm{K} 1}$ contributes to outward potassium current during the last phase of action potential repolarization. The main molecular determinants of cardiac $I_{\mathrm{K} 1}$ are the $\mathrm{K}_{\mathrm{IR}} 2.1$ and $\mathrm{K}_{\mathrm{IR}} 2.2$ proteins expressed from the KCNJ2 and KCNJ12 genes respectively (De Boer et al., 2010a). Defective inward rectifier current may lead, amongst other features, to lethal cardiac arrhythmias in mice and man such as ventricular arrhythmias and atrial fibrillation (Anumonwo and Lopatin, 2010). ECG recording from neonatal mice homozygous for a KCNJ2 null mutation showed lengthening of RR, PR, and QT intervals and QRS broadening. Furthermore, isolated neonatal cardiomyocytes displayed action potential lengthening and ectopic activity (Zaritsky et al., 2001). In contrast, however, null mutation of KCNJ12 generated no cardiac abnormalities (Zaritsky et al., 2001). KCNJ2 loss of function mutation associated with Andersen-Tawil syndrome 1 regularly, but not in each case, displayed long repolarization times (LQT) and biventricular tachycardias. On the other hand, KCNJ2 gain of function mutations have been associated with short QT (Priori et al., 2005), and atrial fibrillation (Xia et al., 2005). Atrial fibrillation was also observed in a mouse model overexpressing KCNJ2 (Li et al., 2004). Finally, KCNJ2 mutations have been associated with Catecholaminergic Polymorphic Ventricular Tachycardia (Vega et al., 2009). Affected $\mathrm{K}_{\mathrm{IR}} 2.1$ and $\mathrm{K}_{\mathrm{IR}} 2.2$ functioning may be the result of amino-acid substitutions (Tristani-Firouzi and Etheridge, 2010), direct channel block (Rodríguez-Menchaca et al., 2008; De Boer et al., 2010b), or changes in expression regulation (Yang et al., 2007).

The dog (Canis lupus familiaris, Cf) with chronic complete atrial-ventricular block (cAVB) is a well established model for drug-induced arrhythmia (Thomsen et al., 2006a). The model acquires its sensitivity and specificity from bradycardia associated volume overload and subsequent cardiac remodeling (Thomsen et al., 2007). The latter process translates into modified contractile, structural, and electrical function (Oros et al., 2008). As a result of electrical remodeling, the so-called repolarization reserve (Roden, 1998; Michael et al., 2009) is diminished as evidenced by increased action potential duration and moreover by increased beat-to-beat variation of repolarization (Thomsen et al., 2006b).

For some species, the molecular basis underlying cardiac electrophysiology, e.g., ion channel, gap junction, and transporter genes and proteins, is well described. However, a functional integration of the individual components to explain a number of electrophysiological phenomena lags behind, despite many decades of research (Coronel, 2010). When considering the dog, the amount of electrophysiological studies by far outnumbers those on the molecular make-up of the underlying ion currents. Nevertheless, the canine genes coding for the electrophysiological building blocks are becoming deciphered rapidly; genome project information can be found at http://www.broadinstitute.org/mammals/dog. The publication of the dog genome has provided an important additional tool that 
stimulated molecular research in this model species (LindbladToh et al., 2005). However, as algorithm driven gene annotation is improving gradually (Flicek, 2007), its results are still often doubtful indicating that experimental confirmation of the genomic structure of the genes of interest is required. To enable our future studies on KCNJ2 and KCNJ12 expression regulation in the dog, it is crucial to characterize the molecular structure of the respective genes. Here we have characterized the canine KCNJ2 and KCNJ12 gene structures by combining genome project data, RTPCR, and $5^{\prime}$ - and $3^{\prime}$-RACE protocols. We demonstrated that the canine KCNJ2 gene consists of two exons harboring its open reading frame (ORF) on exon 2. In contrast, we provided experimental evidence that KCNJ12 is a three exon gene. Its ORF is located on exon 3. No alternative splicing was detected in either heart or brain tissue. We demonstrated that the gene structure is conserved. Canine $\mathrm{K}_{\mathrm{IR}} 2.2$ harbors a peculiar stretch of glycine residues in its carboxy-terminus that is not present in $\mathrm{K}_{\mathrm{IR}} 2.2$ proteins from other species, which did not affect however its expression in cell systems neither its electrophysiological properties.

\section{MATERIALS AND METHODS RT-PCR, $\mathbf{3}^{\prime}$ - AND 5' -RACE}

The investigation conformed to the Guide for the Care and Use of Laboratory Animals published by the US National Institutes of Health (NIH Publication No. 85-23, revised 1996) and was approved by the institutional committee for animal experiments. For all sequencing, samples from at least two purpose bred mongrel dogs were used, that harbored no known genetic defects.

Total RNA was isolated from canine ventricular cells or brain cortex tissue using Trizol (Invitrogen, Breda, The Netherlands) according to the manufacturers recommendations. mRNA was reverse transcribed using oligo $\mathrm{dT}$ and Superscript 2 (Invitrogen). Primer sequences for PCR are given in Table 1. Products were analyzed on ethidium-bromide stained $0.7-1.5 \%$ agarose gels. PCR products were isolated from gel using QIAquick Gel Extraction kit (Qiagen, Venlo, The Netherlands), cloned in pGEMT-easy (Promega, Leiden, The Netherlands) and subsequently sequenced.

$3^{\prime}$ - and $5^{\prime}$-rapid amplification of cDNA ends (RACE) was performed on total RNA using GeneRacer ${ }^{\mathrm{TM}}$ kit (Invitrogen) according to the manufacturers recommendations. In short, total RNA was dephosphorylated and decapped followed by ligation of GeneRacer $^{\mathrm{TM}} 5^{\prime}$ RNA primer. Subsequently, reverse transcription was performed using GeneRacer ${ }^{\mathrm{TM}}$ Oligo dT primer and Superscript 3. Finally, $5^{\prime}$ and $3^{\prime}$ RACE PCR was performed using KCNJ2 and 12 primers as indicated in the results and discussion section, in combination with primers supplied and recommended by the manufacturer. Sequences of primers used for RACE are depicted in Table 1. All PCR products were sequenced by the Dye-terminator sequencing method (BigDye ${ }^{\circledR}$, Applied Biosystems, Nieuwerkerk a.d. IJssel, The Netherlands) on a 3730 Genetic Analyzer (Applied Biosystems).

\section{CLONING AND EXPRESSION ANALYSIS OF CfKCNJ12}

Complete CfKCNJ12 coding sequence was amplified as above using primers KCNJ12\#10se and KCNJ12\#12as as first and KCNJ12\#11se and KCNJ12\#13as as nested primers, and cloned in
Table 1 | Sequences of primers used in this study, sequences are given in $5^{\prime}-3^{\prime}$ orientation.

\begin{tabular}{|c|c|}
\hline \multicolumn{2}{|l|}{ KCNJ2 PRIMERS } \\
\hline KCNJ2\#1se & AGCTGGGTCTTGGGGATTCTGG \\
\hline KCNJ2\#2se & TTGCAGAGCGCACTGGAGCC \\
\hline $\mathrm{KCNJ} 2 \# 3$ as & CATCCACCGCCAGCGAATGT \\
\hline KCNJ2\#4as & ACTGGACGTTGCAGTGGCCG \\
\hline KCNJ2\#5se & TCCGAGGAGACTCGCCGTGAAT \\
\hline KCNJ2\#6se & AGCAGAGTGAGCTCTCCTTCGC \\
\hline \multicolumn{2}{|l|}{ KCNJ12 PRIMERS } \\
\hline KCNJ12\#1se & GCTGCTGCTGACACAGCCTTG \\
\hline KCNJ12\#2se & CGGGGTGTCCAGAGACCTGGGTTC \\
\hline KCNJ12\#3se & GGACCTGGAGACCGACGACTTCG \\
\hline KCNJ12\#4se & GAGCCGCGATGAGGAAGACGAGG \\
\hline KCNJ12\#5se & GGGTTTGAGCAGAATGGGCCTGG \\
\hline KCNJ12\#6as & GATCACCCAGAAGATGATGCC \\
\hline KCNJ12\#7as & GTTGCCGAAGCCGTTGGCACCCGAC \\
\hline KCNJ12\#8as & CCCGCCTGTGTCAGCAGCAGC \\
\hline KCNJ12\#9as & CGATGGTGGTCTGCGTCTCAATGG \\
\hline KCNJ12\#10se & GTGACCGATTCCTCTCCAGCT \\
\hline KCNJ12\#11se & GCAGGAAATGGAAGCTGCTGC \\
\hline KCNJ12\#12as & ACGCTACTGAGTCTGCAACCG \\
\hline KCNJ13\#13as & CCAGGCCCATTCTGCTCAAAC \\
\hline \multicolumn{2}{|c|}{ SUPPLIED GENERACER ${ }^{\mathrm{TM}}$ PRIMERS USED } \\
\hline \multirow[t]{2}{*}{ GeneRacer'M $5^{\prime}$ RNA primer } & CGACUGGAGCACGAGGACACUGACAUG \\
\hline & GACUGAAGGAGUAGAAA \\
\hline \multirow[t]{2}{*}{ GeneRacer ${ }^{\mathrm{TM}}$ Oligo dT primer } & GCTGTCAACGATACGCTACGTAACGGCAT \\
\hline & $\operatorname{GACAGTG}(T)_{24}$ \\
\hline GeneRacer'TM 5' primer & CGACTGGAGCACGAGGACACTGA \\
\hline GeneRacer' ${ }^{\mathrm{TM}} 5^{\prime}$ nested primer & GGACACTGACATGGACTGAAGGAGTA \\
\hline GeneRacer ${ }^{\mathrm{TM}} 3^{\prime}$ primer & GCTGTCAACGATACGCTACGTAACG \\
\hline GeneRacer'TM $3^{\prime}$ nested primer & CGCTACGTAACGGCATGACAGTG \\
\hline
\end{tabular}

pGEM-T-Easy followed by subcloning in pcDNA3.1 using EcoRI. COS-7 cells were transfected with pcDNA-CfKCNJ12 or pcDNAHsKCNJ12 (human KCNJ12) construct using Lipofectamine 2000 (Invitrogen) according to the manufacturers recommendations. Twenty-four hours post-transfection, cells were harvested in lysis buffer [20 mM HEPES, pH 7.6, $125 \mathrm{mM} \mathrm{NaCl,} \mathrm{10 \%} \mathrm{(v/v)} \mathrm{glycerol,}$ 1 mM EDTA, 1 mM EGTA, 1 mM Dithiothreitol, 1\% (v/v) Triton $\mathrm{X}-100]$. Subsequently, $20 \mu \mathrm{g}$ protein lysate was separated by $10 \%$ SDS-PAGE and blotted onto nitrocellulose membrane. Blots were blocked with $5 \%(\mathrm{v} / \mathrm{v})$ fresh chicken egg yolk in TBST [20 mM Tris-Cl, pH 8.0, $150 \mathrm{mM} \mathrm{NaCl}, 0.05 \%$ (v/v) Tween-20] for $1 \mathrm{~h}$ at room temperature. $\mathrm{K}_{\mathrm{IR}} 2.2$ protein was detected using $\mathrm{K}_{\mathrm{IR}} 2.1 / 2$ antibody (cat. no. sc-18708, Santa Cruz Biotechnology, Santa Cruz, CA, USA) and Donkey-anti-Goat horseradish peroxidase (cat. no. 705-035-003, Jackson ImmunoResearch, West Grove, PA, USA). Standard ECL procedure was used for final detection (Santa Cruz Biotechnology). Localization studies were performed following transient transfection in HEK293 cells as described previously (Jansen et al., 2008).

\section{PATCH CLAMP ELECTROPHYSIOLOGY}

HEK293T cells cultured on glass coverslips were co-transfected with $0.5 \mu \mathrm{g}$ pcDNA-K $\mathrm{IR}_{\mathrm{IR}} 2.2$ and $0.5 \mu \mathrm{g}$ pEGFP1 expression 


\title{
A canine $K C N J 2$ gene structure
}

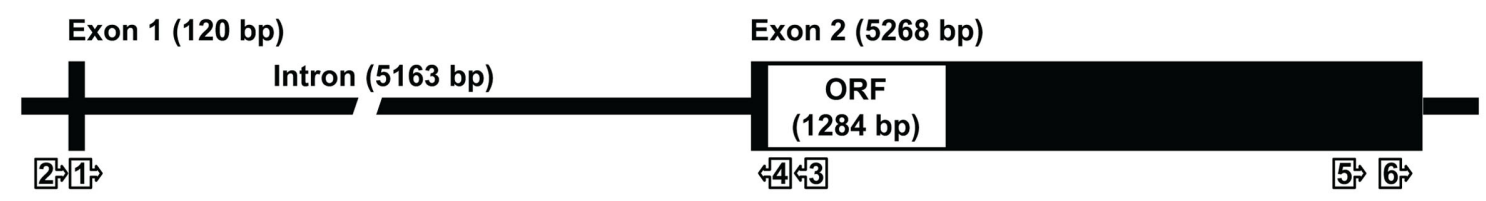

\section{B transcription initiation site}

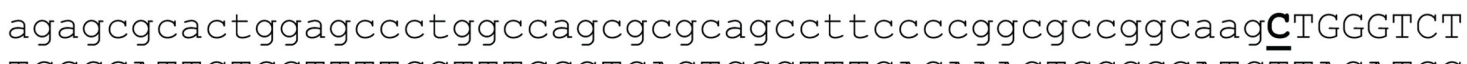
TGGGGATTCTGGTTTTGCTTTGGCTCACTCGCTTTCACAAACTGCCGGATCTTACATGC

\section{c splice sites}

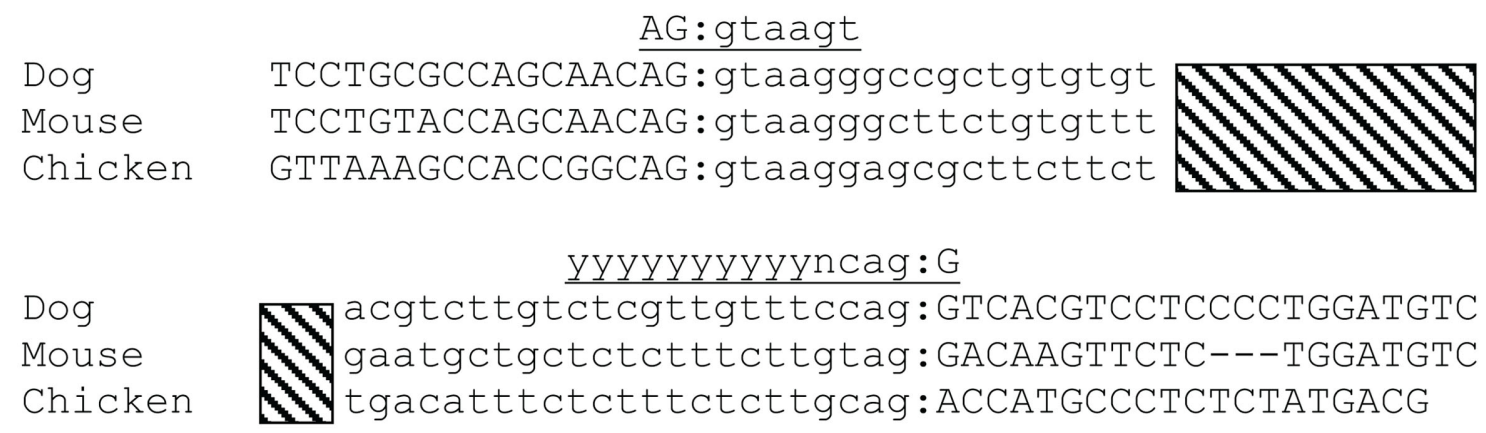

D poly A signal and transcript termination

\author{
EXON 2 3'UTR \\ AATAAA ATTAAA
}

TTCTA $\overline{A A T A A A} A \overline{A T T A A A} A A C T G A$ : agacaaattggtgcaagaatctgcgggcttcct TTCTAAATAAAAAATTAAAAACTGAAGACA : aattggtgcaagaatctgcgggcttcct TTCTAAATAAAAAATTAAAAACTGAAGACAAATTGGTGCA : agatctgcgggcttcct TTCTAAATAAAAAATTAAAAACTGAAGACAAATTGGTGCAAGA : atctgcggccttcct

FIGURE 1 | Canine $\boldsymbol{K} \boldsymbol{C N} \boldsymbol{J} \mathbf{2}$ genomic structure. (A) Representation of the KCNJ2 gene indicating lengths of first and second exons, intron and the open reading frame (ORF). Relative position of $K C N J 2$ specific primers used for intron/exon mapping, 5' and 3' RACE are indicated by numbered box arrows. (B) Transcription initiation site (bold and underlined) with upstream (lower case) and downstream exon 1 (upper case) sequences. (C) Sequence surrounding exon 1-intron and intron-exon 2 splicing sites of dog, mouse, and chicken KCNJ2 genes. Hatched bar indicates intron region. Exon 1 and exon 2 sequences are indicated in upper case lettering, intron sequence in lower case. Consensus splicing sequences are indicated above the sites (underlined). (D) Four alternative 3' transcript termini (bold). Exon 2 sequences are indicated in upper case, downstream genomic sequences in lower case. Consensus termination signals are indicated above the sequences (underlined). constructs as described aboved. Patch clamp measurements were done using a AxoPatch 200B amplifier controlled by pClamp 9 software (Molecular devices, Sunnyvale, CA, USA). Voltage clamp measurements of whole cell $I_{\mathrm{K} 1}$ were performed by applying $1 \mathrm{~s}$ test pulses ranging between -120 and $+40 \mathrm{mV}$, in $10 \mathrm{mV}$ increments, from a holding potential of $-40 \mathrm{mV}$, and with series resistance compensation of at least $70 \%$. Steady state current at the end of the pulse was normalized to cell capacitance and plotted versus test potential (corrected for liquid junction potential). Patch pipettes were made with a Sutter P-2000 puller (Sutter Instrument,
Novato, CA, USA) and had resistances of 2-3 M 2 . Extracellular solution for whole cell $I_{\mathrm{K} 1}$ measurements contained (in $\mathrm{mmol} / \mathrm{L}$ ): $\mathrm{NaCl} 140, \mathrm{KCl} 5.4, \mathrm{CaCl}_{2} 1, \mathrm{MgCl}_{2}$ 1, glucose 6, $\mathrm{NaHCO}_{3}$ 17.5, HEPES 15, pH 7.4/NaOH. Pipette solution contained potassium gluconate 125, $\mathrm{KCl} 10$, HEPES 5, EGTA 5, $\mathrm{MgCl}_{2} 2, \mathrm{CaCl}_{2}$ 0.6, $\mathrm{Na}_{2}$ ATP 4, pH 7.20/KOH.

To evaluate the blocking effect of polyamine on $\mathrm{K}_{\mathrm{IR}} 2.2$ channel currents from both human and dog KCNJ12 genes, we analyzed chord conductance values from $I-V$ relationship by inside-out patch clamp experiments as previously described (Ishihara and 
A canine $\mathrm{KCNJ} 12$ gene structure

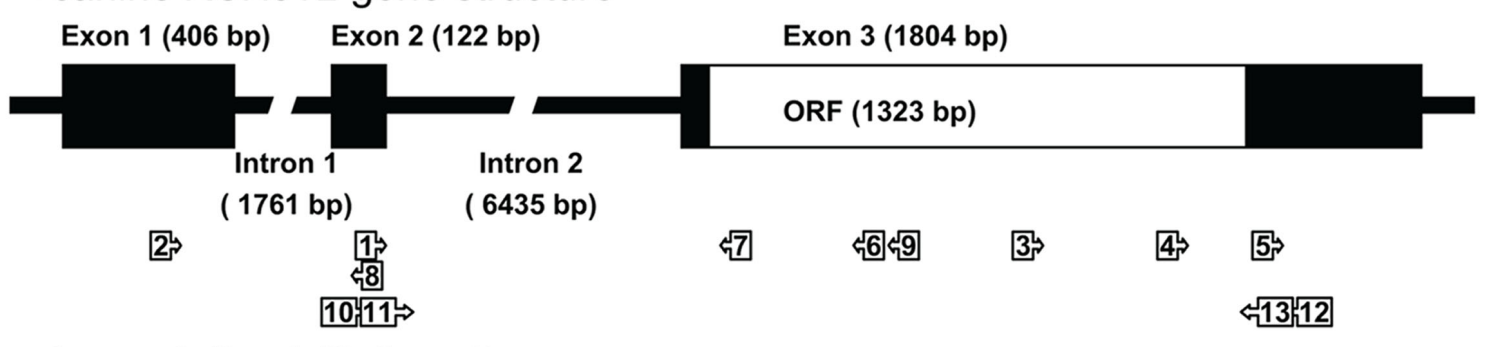

B transcription initiation site

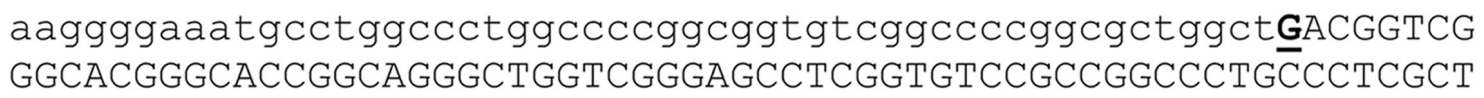

c splice sites

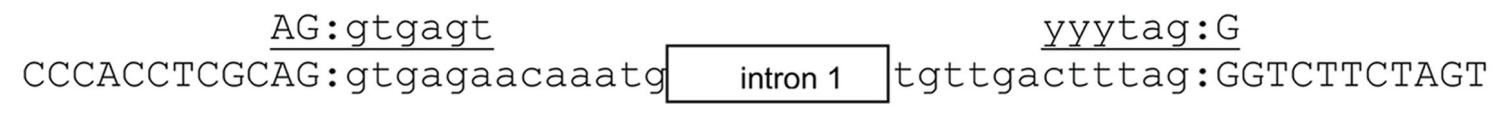

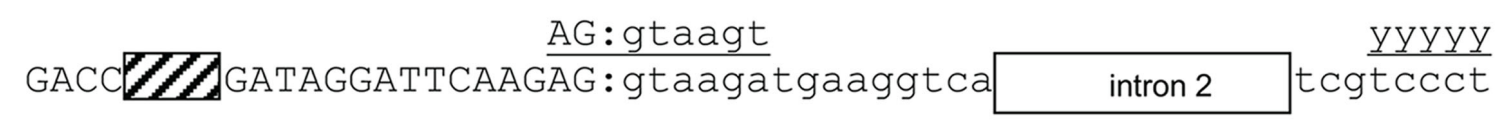

yyyncag: $\mathrm{G}$

gttgcag: GAGCCGCCCCCCG

D poly A signal and transcript termination

EXON $33^{\prime}$ UTR
$\frac{\text { ATTAAA }}{\text { AATAAA }}$
AACCTTAGCTTGATAAGACTGTTTAC: aaaaaaaaaaaaatt Aacatgtgatt

FIGURE 2 | Canine $\boldsymbol{K C N J 1 2 ~ g e n o m i c ~ s t r u c t u r e . ~ ( A ) ~ R e p r e s e n t a t i o n ~ o f ~ t h e ~}$ $K C N J 12$ gene indicating lengths of first, second, and third exons, first and second intron, and the open reading frame (ORF). Relative position of KCNJ12 specific primers used for intron/exon mapping, $5^{\prime}$ and $3^{\prime}$ RACE are indicated by numbered box arrows 1-9. Relative positions of $K C N J 12$ specific primers for cloning the ORF are indicated by numbered box arrows 10-13. (B) Transcription initiation site (bold and underlined) with upstream (lower case) and downstream exon 1 (upper case) sequences. (C) Sequence surrounding exon 1-intron 1, intron 1-exon 2, exon 2-intron 2, and intron 2-exon 3 splicing sites of dog KCNJ12. Open bars indicate intron regions, hatched bar indicates exon 2 region. Exon sequences are indicated in upper case lettering, intron sequences in lower case. Consensus splicing sequences are indicated above the sites (underlined). (D) $3^{\prime}$ transcript terminus (bold). Exon 3 sequence is indicated in upper case, downstream genomic sequence in lower case. Consensus termination signals are indicated above the sequences (underlined).
Ehara, 2004). The pipette (extracellular) solution contained (mM): $145 \mathrm{KCl}, 1 \mathrm{CaCl}_{2}$, and $5 \mathrm{HEPES}$ (pH 7.4 with $\mathrm{KOH}$ ). The bath (intracellular) solution contained $(\mathrm{mM}) 125 \mathrm{KCl}, 4$ EDTA $(2 \mathrm{~K})$, $7.2 \mathrm{~K}_{2} \mathrm{HPO}_{4}$, and $2.8 \mathrm{KH}_{2} \mathrm{PO}_{4}(\mathrm{pH} 7.2$ with $\mathrm{KOH}$ ). Spermine was used in the concentration of $0.1,1$, and $10 \mu \mathrm{M}$. Currents were recorded from inside-out membrane patches at room temperature $\left(22^{\circ} \mathrm{C}\right.$; De Boer et al., 2010b). The holding potential was set to $0 \mathrm{mV}$, and test pulses were applied between -60 and $+90 \mathrm{mV}$ in $5 \mathrm{mV}$ steps with $-40 \mathrm{mV}$ hyperpolarizing pre-pulse. Current amplitude was measured at $2 \mathrm{~s}$ after the onset of the test pulse. For this evaluation, we used the equation $G=I /\left(V-V_{\text {rev }}\right)$. In our study, the values of $V_{\text {rev }}$ measured by a ramp protocol $(40 \mathrm{mV} / \mathrm{s})$ were always near $0 \mathrm{mV}$ (between $\pm 2 \mathrm{mV}$ ). Conductance values for each test voltage were normalized by the maximum value. Furthermore, we evaluated the time-dependent decay of $\mathrm{K}_{\mathrm{IR}} 2.2$ channel current just after the onset of test pulse. Single exponential fitting of the current was performed by Microcal Origin (ver.8, Microcal Software, Northampton, MA, USA). 


\section{RESULTS AND DISCUSSION MAPPING OF THE $K C N J 2$ GENE}

To experimentally map the canine KCNJ2 gene (Figure 1A), we first retrieved the putative KCNJ2 genomic sequence from chromosome 9 using the canine genome project data (accession number NC_006591). Homology comparison (Vector NTI suite 8 , operating on Clustal $\mathrm{W}$ algorithm) with the mapped murine KCNJ2 (Redell and Tempel, 1998) indicated putative regions for a first and second exon. Based on these, PCR primers were designed for RT-PCR, $5^{\prime}$ - and $3^{\prime}$-RACE (Table 1). RNA was isolated from canine ventricular cardiomyocytes. RT-PCR using primer KCNJ2\#1se and KCNJ2\#3as designed at the putative exon 1 and exon 2 sequences respectively revealed one single product of approximately $590 \mathrm{bp}$. Exon/intron boundaries were determined by sequencing of the products and aligned against the genomic DNA sequences. Boundaries were found to conform to consensus exon/intron and intron/exon sites, and high levels of homology were found at the splice sites when compared with mouse and chicken (Figure 1C). No additional exons were found in this intron region. No differences with respect to the genome reference sequence were observed.

The transcription initiation site (TIS) was mapped by $5^{\prime}$-RACE using primer KCNJ2\#3as and the nested primer KCNJ2\#4as originated from exon 2. Only a single TIS was obtained in this way (Figure 1B). RT-PCR using primer KCNJ2\#2se, located directly upstream of the TIS and KCNJ2\#4as yielded no product. In the mouse KCNJ2 gene, four TISs were determined located in a stretch of eight nucleotides (Redell and Tempel, 1998). In chicken, also four TISs were mapped, of which three are located adjacent to each other, while a fourth was located approximately 20 nucleotides upstream of these (Mutai et al., 2004).

For 3'-RACE, nested PCR using KCNJ2\#5se and subsequent KCNJ2\#6se (nested) combined with antisense primers provided by the fabricant was performed. This revealed the presence of four different transcripts (heterogeneity of mRNA cleavage) terminating after two consensus poly (A) signals, namely AAUAAA and AUUAAA (Zhao et al., 1999; Figure 1D). While for mouse, the transcript was reported to end following the first consensus poly (A) (Redell and Tempel, 1998), we found transcript termination only following the second consensus poly (A) site. Heterogenous mRNA cleavage has been noted in approximately $50 \%$ of mammalian transcripts with a single poly (A) signal (Tian et al., 2005), however its biological significance, if any, is unknown. In the case of KCNJ2, heterogenic mRNA cleavage may result from the presence of two poly (A) sites. Furthermore, it has been suggested that the RNA cleavage by the polyadenylation enzyme complex is imprecise in nature (Tian et al., 2005). Resulting sequences and annotations can be found at the following GenBank accession numbers: HM209045 for $5^{\prime}$ sequences, HM209046 for $3^{\prime}$ sequences, and BK007085 for complete gene annotation.

When comparing the overall KCNJ2 structure from dog with those of mouse and chicken (Table 2) we notice a very similar make-up existing of a short first exon (103-168 bp) containing untranslated mRNA (UTR) only, a large intron varying between $\sim 4900$ and $\sim 5500 \mathrm{bp}$ and a large second exon containing the entire ORF. While the length of the second exon is reasonably well conserved between dog and mouse (5268 and 5316 bp
Table 2 | Comparison of canine $K C N J 2$ and $K C N J 12$ gene structure with that of other species.

\begin{tabular}{lllllll}
\hline & \multicolumn{3}{c}{ KCNJ2 } & & \multicolumn{2}{c}{ KCNJ12 } \\
\cline { 2 - 3 } \cline { 6 - 7 } & Dog & Mouse $^{\mathbf{1}}$ & Chicken $^{2}$ & & Dog & Human $^{\mathbf{3} 4}$ \\
\hline Exon 1 & 120 & 168 & 103 & & 406 & $>192$ \\
Intron 1 & 5163 & $\sim 5500$ & $\sim 4900$ & & 1761 & n.d. \\
Exon 2 & 5268 & $\sim 5316$ & 2020 & & 122 & $\sim 123$ \\
Intron 2 & n.a. & n.a. & n.a. & & 6435 & n.d. \\
Exon 3 & n.a. & n.a. & n.a. & & 1804 & $\sim 1883$ \\
ORF & 1284 & 1287 & 1284 & & 1323 & 1302 \\
5'UTR & 338 & 403 & 319 & & 584 & $>369$ \\
3'UTR & 3766 & $\sim 3800$ & 550 & & 425 & $\sim 527$ \\
\hline
\end{tabular}

Numbers are given in base pairs. ORF, open reading frame; UTR, untranslated region. 'Redell and Tempel (1998), '2Mutai et al. (2004), ${ }^{3}$ Hugnot et al. (1997), ${ }^{4}$ Ryan et al. (2010).

respectively), that of the chicken is much shorter (2020 bp). Finally, the gene structure as presented here is not annotated in NCBI Entrez Gene (GeneID 403717, accessed at July 19, 2011), that annotates the coding region only.

\section{MAPPING OF THE KCNJ12 GENE}

For mapping KCNJ12 (Figure 2A) experimentally, a similar approach was used as for KCNJ2. The putative KCNJ12 sequence was derived from chromosome 5 (accession number NC_006587). Next, sense (KCNJ12\#1se) and antisense (KCNJ12\#6as) primers were generated within exon 2 (which was then considered as the first exon) and exon 3 sequences, respectively. Subsequent sequencing revealed the exon 2 - intron 2 - exon 3 boundaries (Figure 2C). Upon $5^{\prime} \mathrm{RACE}$ using KCNJ12\#7as located in exon 3 and the nested primer KCNJ12\#8as located in exon 2, an additional exon of $406 \mathrm{bps}$ was discovered (Figure 2A). Resulting sequences and annotations can be found at GenBank accession numbers HQ378597. RT-PCR using primers located in exon 1 (KCNJ12\#2se) and exon 3 (KCNJ12\#7as for cortex and KCNJ12\#9as for right ventricle) sequences yielded a single product in heart and brain tissue (Figure 3A). Upon sequencing, the latter was found as being identical to the ventricular product. No evidence was found for alternative splicing, either by $5^{\prime}$ RACE neither by inter-exon RT-PCR. Exon/intron boundaries were determined by sequencing PCR products and compare these to genomic DNA (Figure 2C). As for KCNJ2, boundaries were found to conform to consensus exon/intron and intron/exon sites. 5'-RACE using primer KCNJ12\#7as and primer KCNJ12\#8as identified one TIS (Figure 2B). No putative TATA box was found upstream of the initiation site. $3^{\prime}$-RACE using KCNJ12\#3se and two different nested primers (KCNJ12\#4se and KCNJ12\#5se), all located in exon 3, identified only one termination site (Figure 2D). No genuine termination signal was identified in this gene. Finally, no differences with respect to the genome reference sequence were observed.

To our knowledge, no KCNJ12 gene structure from other species has been published. Indirectly however, Ryan et al. (2010) indicate that the genomic structure of $K C N J 12$ is very similar with that of KCNJ16. They indicate that KCNJ12 is a three exon gene 
A

ventricle

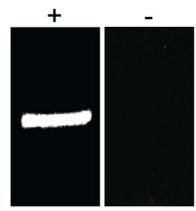

cortex

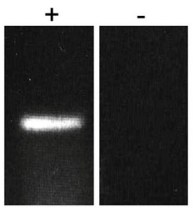

B

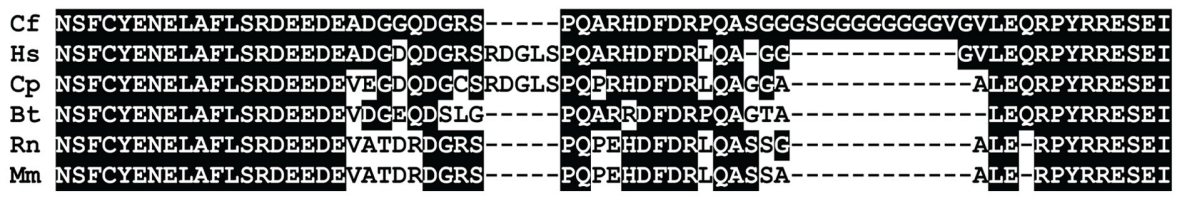

FIGURE 3 | (A) KCNJ12 mRNA RT-PCR using primers located in exon 1 and 3 regions yields a single amplification product. Left panel, chronic AV block dog

indicates minus RT control. (B) Homology comparison of dog (Cf), human (Hs), right ventricle; right panel control dog cortex. + Indicates prior RT-reaction, -

guinea pig $(\mathrm{Cp})$, bovine $(\mathrm{Bt})$, rat $(\mathrm{Rn})$, and mouse $(\mathrm{Mm}) \mathrm{K}_{\mathrm{IR}} 2.2$ carboxy-termini.

Conserved residues are depicted in white font on black background.

\section{A}

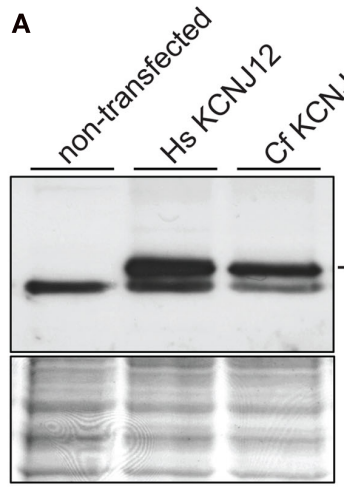

C
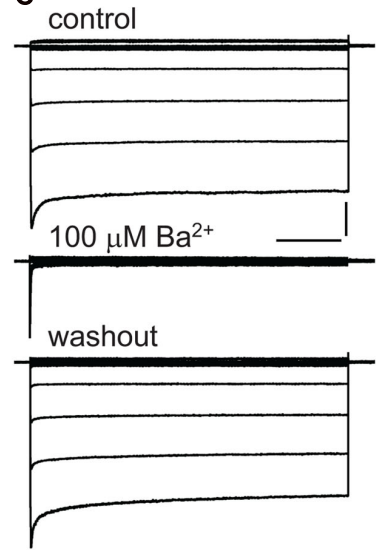

B
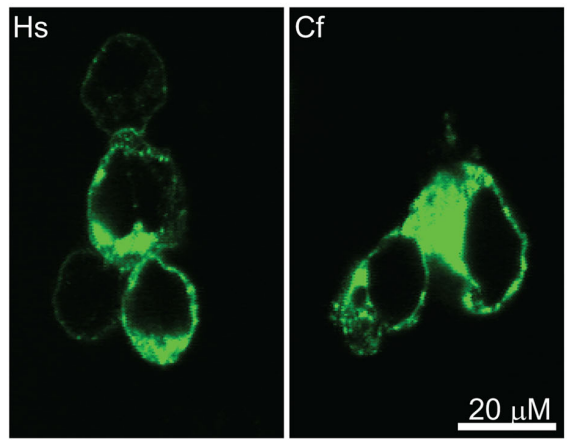

D

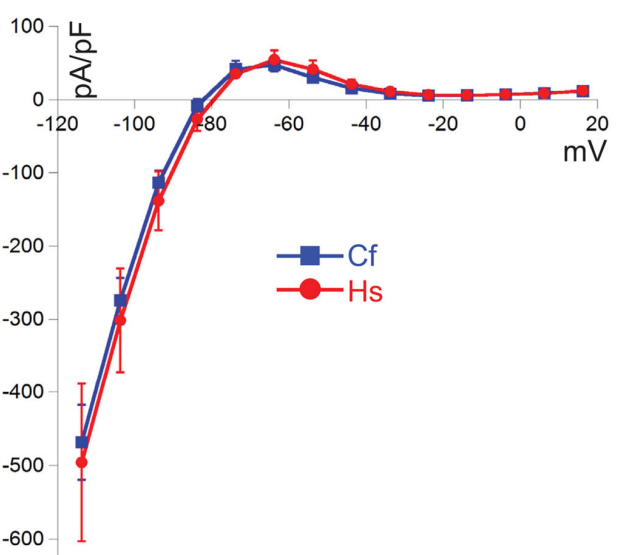

FIGURE 4 | Characterization of $\mathbf{C f K}_{\mathrm{IR}_{\mathrm{R}}}$ 2.2. (A) Western blot depicting human ( $\mathrm{Hs}$ ) and dog (Cf) $\mathrm{K}_{\mathrm{IR}} 2.2$ expression upon ectopic expression in COS-7 cells. Non-transfected cells were used as negative control. (B) Subcellular localization of ectopic human (Hs) and dog (Cf) $K_{\mathbb{I R}} 2.2$ in HEK293 cells. (C) Current traces of $\mathrm{CfK}_{\mathrm{IR}} 2.2$ carried $I_{\mathrm{K} 1}$, before (control), upon $100 \mu \mathrm{M} \mathrm{BaCl}_{2}$ application $\left(\mathrm{Ba}^{2+}\right)$, and following washout (washout). Horizontal bar: $200 \mathrm{~ms}$; Vertical bar: $2 \mathrm{nA}$. (D) Current-Voltage relationship of dog ( $\mathrm{C} f$, blue squares and line; $n=8$, average $\pm \mathrm{SEM}$ ) and human ( $\mathrm{Hs}$, red circles and line; $n=4$, average \pm SEM) $K_{\mathrm{IR}} 2.2$ carried $I_{\mathrm{K} 1}$ in HEK293T cells. with strong homology to KCNJ16 except for exon 1, which is longer in KCNJ12 than in KCNJ16. KCNJ12 intron lengths were not reported. When comparing our dog KCNJ12 sequence with that of human, strong similarity is seen for the length of exon 2 

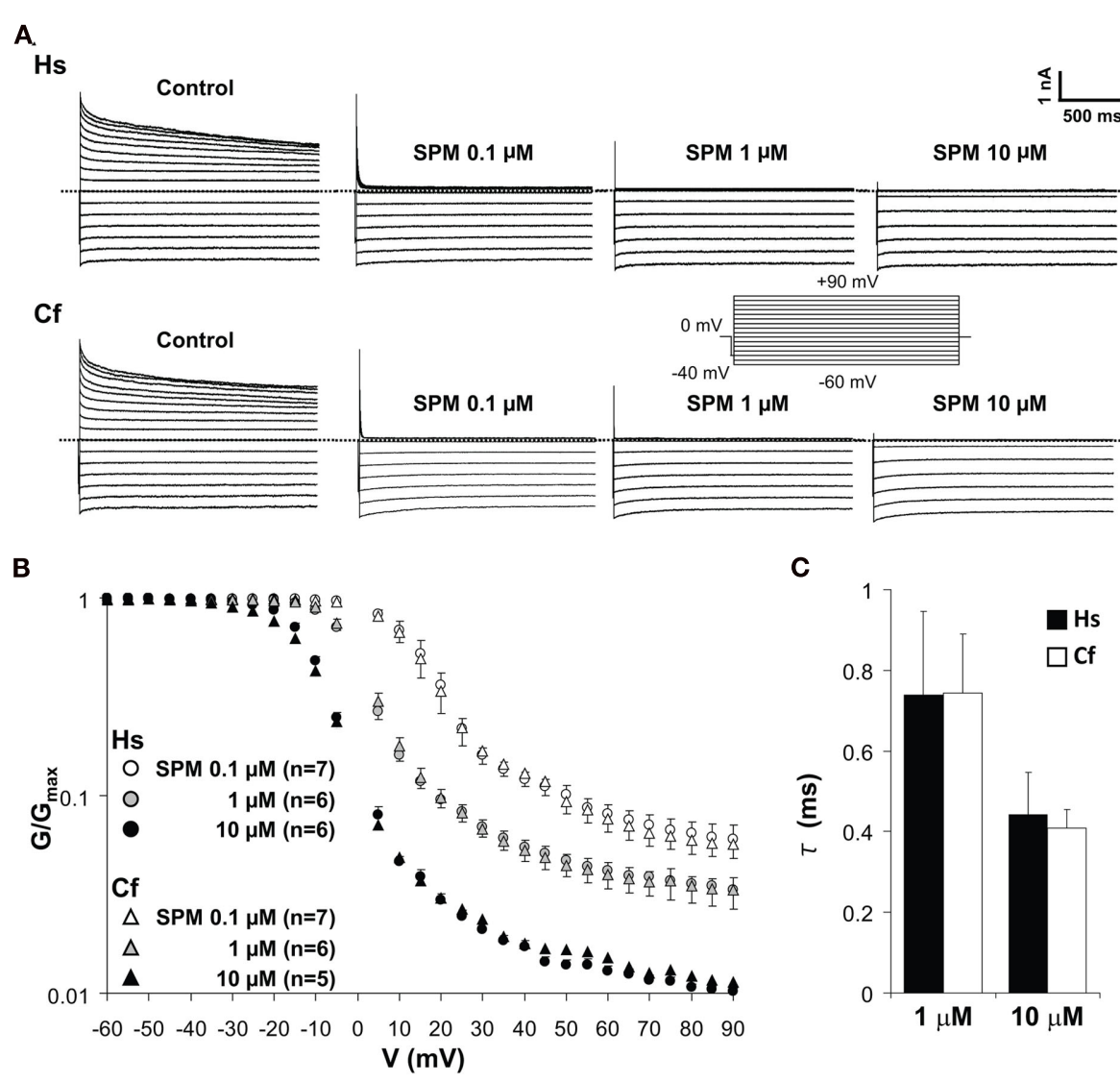

FIGURE 5 | Spermine-induced block of human (Hs) and dog (Cf) $K_{\mathrm{IR}} 2.2$ channels. (A) Representative traces of $K_{I R} 2.2$ channel currents in the absence and presence of $0.1,1$, and $10 \mu \mathrm{M}$ of spermine. Inset: pulse protocol, currents were elicit by $10 \mathrm{mV}$ step test pulses from -60 to $+90 \mathrm{mV}$. (B) Comparison of
$V-G$ relationships of human and dog $K_{\mathbb{R}} 2$.2. The scale of $G / G_{\max }$ is logarithmic. Test pulses were applied in $5 \mathrm{mV}$ steps from -60 to $+90 \mathrm{mV}$, and $G$ was calculated for each voltage. (C) The comparison of time constant of $K_{\mathrm{IR}} 2.2$ channel currents at $+80 \mathrm{mV}$ in the presence of 1 and $10 \mu \mathrm{M} \mathrm{SPM}$. and 3 (Table 2). Furthermore, dog KCNJ12 is a three exon gene too, with its entire ORF located on Exon 3. Unfortunately, due to the lack of more specific sequence information of the human form, no reliable comparisons can be made further. Finally, the gene structure as presented here is different from the one that is annotated in NCBI Entrez Gene (GeneID 403760, accessed at July $19,2011)$, that annotates the coding region on five separate exons. Furthermore, no $5^{\prime}$ UTR is presented, while the $3^{\prime}$ UTR is $\sim 22 \mathrm{bp}$ in length.

\section{ELECTROPHYSIOLOGICAL ANALYSIS OF K K $\mathbf{I R} 2.2$}

Translating genomic KCNJ12 sequence revealed a $\mathrm{K}_{\mathrm{IR}} 2.2$ protein containing a peculiar stretch of glycine residues near the carboxyterminus. Apparently this was not a sequencing artifact as RT-PCR using primers located in exon 1 and 3 confirmed the finding in mRNA derived from left ventricle and cortex (Figure 3A). Although the glycine rich region was not identified in other species (Figure 3B), it is found in a less-conserved region of the protein. Glycine rich amino-acid stretches are found in many other proteins, however no function has been addressed. To investigate a potential functional consequence, the complete channel was cloned. Expression in COS-7 cells revealed a protein with an apparent $M_{\mathrm{W}}$ of $\sim 50 \mathrm{kDa}$ (Figure $4 \mathrm{~A}$ ). Upon transfection in HEK293 cells, strong expression of canine $\mathrm{K}_{\mathrm{IR}} 2.2$ was seen at the plasma membrane, comparable with that of human $\mathrm{K}_{\mathrm{IR}} 2.2$ (Figure 4B; Kaibara et al., 2002). When expressed in HEK293T cells, patch clamp analysis demonstrated the presence of a typical barium sensitive inward rectifying current (Figure 4C) which was indistinguishable from human $\mathrm{K}_{\mathrm{IR}} 2.2$ carried $I_{\mathrm{K} 1}$ (Figure $4 \mathrm{D}$ ).

$\mathrm{K}_{\mathrm{IR}} 2 . \mathrm{x}$ channels show dose-dependent changes of blocking profile by spermine (SPM) and spermidine (Ishihara and Yan, 2007). To evaluate the electrophysiological properties of canine $\mathrm{K}_{\mathrm{IR}} 2.2$ into more detail, voltage-dependent blockade of $\mathrm{K}_{\mathrm{IR}} 2.2$ channel current by different concentrations of SPM was analyzed by determining the $V-G$ relationship (Figures 5A,B). The representative current traces measured by inside-out patch clamp show that outward $I_{\mathrm{K} 1}$ currents mediated by human and dog KCNJ12 are blocked in the presence of $0.1-10 \mu \mathrm{M}$ of SPM in a dose-dependent manner. The $V-G$ curve shifted to more negative voltages upon increasing the SPM concentration. No significant difference in $V-G$ relations at either SPM concentration was observed (Figure 5B). In the presence of physiological levels of SPM (1 and $10 \mu \mathrm{M}$; Yan et al., 2005), human and $\operatorname{dog} \mathrm{K}_{\mathrm{IR}} 2.2$ channels displayed similar time-dependent decay at $+80 \mathrm{mV}[1 \mu \mathrm{M}$ : 
$0.74 \pm 0.21(\mathrm{SEM} ; n=5)$ and $0.74 \pm 0.15(n=6) \mathrm{ms} ; 10 \mu \mathrm{M}$ : $0.44 \pm 0.10(n=5)$ and $0.41 \pm 0.06(n=5) \mathrm{ms}$ for human and dog respectively; Figure $\mathbf{5 C}$ ]. Our results suggested that there is no difference between human and $\operatorname{dog} \mathrm{K}_{\mathrm{IR}} 2.2$ with respect to SPM affinity and speed of binding. As the glycine rich domain is not conserved among species and we observed no differences in electrophysiological parameters tested, we speculate that it has no relevance for canine $\mathrm{K}_{\mathrm{IR}} 2.2$ function and its interaction with polyamines.

Only few studies have addressed $\mathrm{K}_{\mathrm{IR}} 2.2$ in ventricular tissue of large animal models, and currently, we can only speculate on the function and significance of canine $\mathrm{K}_{\mathrm{IR}} 2.2$ expression in the heart. Ojaimi et al. (2007) measured expression of left ventricular genes upon transition to pacing induced heart failure in the dog heart. Their data indicate clear expression of both KCNJ2 and KCNJ12 in the left ventricle (NCBI gene expression omnibus (GEO) profiles and GDS2424/1582618_at and GDS2424/1582977_at, respectively), however, no change was found upon transition into heart failure. Zobel et al. (2003) report $\mathrm{K}_{\mathrm{IR}} 2.2$ expression in

\section{REFERENCES}

Anumonwo, J. M., and Lopatin, A. N. (2010). Cardiac strong inward rectifier potassium channels. J. Mol. Cell. Cardiol. 48, 45-54.

Coronel, R. (2010). Challenging cardiac electrophysiology. Front. Physiol. 1:8. doi:10.3389/fphys.2010.00008

De Boer, T. P., Houtman, M. J. C., Compier, M., and Van der Heyden, M. A. G. (2010a). The mammalian KIR2.x inward rectifier ion channel family: expression pattern and pathophysiology. Acta Physiol. 199, 243-253.

De Boer, T. P., Nalos, L., Stary, A., Kok, B., Houtman, M. J. C., Antoons, G., Van Veen, T. A. B., Beekman, J. D. M., De Groot, B. L., Opthof, T., Rook, M. B., Vos, M. A., and Van der Heyden, M.A. G. (2010b). The anti-protozoal drug pentamidine blocks KIR2.xmediated inward rectifier current by entering the cytoplasmic pore region of the channel. Br. J. Pharmacol. 159, 1532-1541.

Dhamoon, A. S., and Jalife, J. (2005). The inward rectifier current (IK1) controls cardiac excitability and is involved in arrhythmogenesis. Heart Rhythm 2, 316-324.

Flicek, P. (2007). Gene prediction: compare and CONTRAST. Genome Biol. 8, 233.

Gaborit, N., Le Bouter, S., Szuts, V., Varro, A., Escande, D., Nattel, S., and Demolombe, S. (2007). Regional and tissue specific transcript signatures of ion channel genes in the non-diseased human heart. J. Physiol. 582, 675-693.

Hugnot, J. P., Pedeutour, F., Le Calvez, C., Grosgeorge, J., Passage, E.,
Fontes, M., and Lazdunski, M. (1997). The human inward rectifying $\mathrm{K}+$ channel Kir2.2 (KCNJ12) gene: gene structure, assignment to chromosome 17p11.1, and idenrepeat polymorphism. Genomics 39, 113-116.

Ishihara, K., and Ehara, T. (2004). Two modes of polyamine block regulating the cardiac inward rectifier $\mathrm{K}+$ current IK1 as revealed by a study of the Kir2.1 channel expressed in a human cell line. J. Physiol. 556, 61-78.

Ishihara, K., and Yan, D. H. (2007). Low-affinity spermine block mediating outward currents through Kir2.1 and Kir2.2 inward rectifier potassium channels. J. Physiol. 583, 891-908.

Jansen, J. A., De Boer, T. P., Wolswinkel, R., Van Veen, T. A., Vos, M. A., Van Rijen, H. V. M., and Van der Heyden, M. A. G. (2008). Lysosome mediated Kir2.1 breakdown directly influences inward rectifier current density. Biochem. Biophys. Res. Commun. 367, 687-692.

Kaibara, M., Ishihara, K., Doi, Y., Hayashi, H., Ehara, T., and Taniyama, K. (2002). Identification of human Kir2.2 (KCNJ12) gene encoding functional inward rectifier potassium channel in both mammalian cells and Xenopus oocytes. FEBS Lett. 531, 250-254.

Li, J., McLerie, M., and Lopatin, A. (2004). Transgenic upregulation of IK1 in the mouse heart leads to multiple abnormalities of cardiac excitability. Am. J. Physiol. Heart Circ. Physiol. 287, H2790-H2802. tification of a simple tandem

isolated rabbit ventricular myocytes. Upon culturing, expression levels remained whereas $\mathrm{K}_{\mathrm{IR}} 2.1$ expression decreased by $80 \%$. In humans, $\mathrm{K}_{\mathrm{IR}} 2.2$ displayed a more pronounced regional expression than $\mathrm{K}_{\mathrm{IR}} 2.1$, i.e., a preferential expression in the epicardium of the right ventricle compared to the endocardium (Gaborit et al., 2007).

\section{CONCLUSION}

We were able to experimentally map the canine KCNJ2 and KCNJ12 genes. KCNJ2 is a two exon gene that displays a similar organization as the mouse homolog, while it differs with the chicken variant in the length of exon 2 only. KCNJ12 is a three exon gene, which resembles the human organization. No alternative splicing in KCNJ12 was detected in heart or brain tissue. Canine KCNJ12 produced genuine $\mathrm{K}_{\mathrm{IR}} 2.2$ carried $I_{\mathrm{K} 1}$ upon expression in HEK293T cells.

\section{ACKNOWLEDGMENTS}

Dr. H. Takanari was supported during this work through the SENSHIN Medical Research Foundation.

Lindblad-Toh, K., Wade, C. M., Mikkelsen, T. S., Karlsson, E. K. Jaffe, D. B., Kamal, M., Clamp, M., Chang, J. L., Kulbokas, E. J. III, Zody, M. C., Mauceli, E., Xie, X., Breen, M., Wayne, R. K., Ostrander, E. A., Ponting, C. P., Galibert, F., Smith, D. R., DeJong, P. J., Kirkness, E., Alvarez, P., Biagi, T., Brockman, W., Butler, J., Chin, C. W., Cook, A., Cuff, J., Daly, M. J., DeCaprio, D., Gnerre, S., Grabherr, M., Kellis, M., Kleber, M., Bardeleben, C., Goodstadt, L., Heger, A., Hitte, C., Kim, L., Koepfli, K. P., Parker, H. G. Pollinger, J. P., Searle, S. M., Sutter, N. B., Thomas, R., Webber, C. Baldwin, J., Abebe, A., Abouelleil, A., Aftuck, L., Ait-Zahra, M., Aldredge, T., Allen, N., An, P., Anderson, S., Antoine, C., Arachchi, H., Aslam, A., Ayotte, L., Bachantsang, P., Barry, A., Bayul, T., Benamara, M., Berlin, A. Bessette, D., Blitshteyn, B., Bloom, T., Blye, J., Boguslavskiy, L., Bonnet, C., Boukhgalter, B., Brown, A., Cahill, P., Calixte, N., Camarata, J., Cheshatsang, Y., Chu, J., Citroen, M., Collymore, A., Cooke, P., Dawoe, T., Daza, R., Decktor, K., DeGray, S., Dhargay, N., Dooley, K., Dooley, K., Dorje, P., Dorjee, K., Dorris, L., Duffey, N., Dupes, A., Egbiremolen, O. Elong, R., Falk, J., Farina, A., Faro, S., Ferguson, D., Ferreira, P., Fisher, S., FitzGerald, M., Foley, K., Foley, C., Franke, A., Friedrich, D., Gage, D., Garber, M., Gearin, G., Giannoukos, G., Goode, T., Goyette, A., Graham, J., Grandbois, E., Gyaltsen, K., Hafez, N., Hagopian, D., Hagos, B., Hall, J., Healy, C., Hegarty, R., Honan, T., Horn, A., Houde, N., Hughes,
L., Hunnicutt, L., Husby, M., Jester, B., Jones, C., Kamat, A., Kanga, B. Kells, C., Khazanovich, D., Kieu, A. C., Kisner, P., Kumar, M., Lance, K., Landers, T., Lara, M., Lee, W., Leger, J. P., Lennon, N., Leuper, L., LeVine, S., Liu, J., Liu, X., Lokyitsang, Y., Lokyitsang, T., Lui, A., Macdonald, J., Major, J., Marabella, R., Maru, K., Matthews, C., McDonough, S., Mehta, T., Meldrim, J., Melnikov, A., Meneus, L., Mihalev, A., Mihova, T., Miller, K., Mittelman, R., Mlenga, V., Mulrain, L., Munson, G., Navidi, A., Naylor, J., Nguyen, T., Nguyen, N., Nguyen, C., Nguyen, T., Nicol, R., Norbu, N., Norbu, C., Novod, N., Nyima, T., Olandt, P., O’Neill, B., O’Neill, K., Osman, S., Oyono, L., Patti, C., Perrin, D., Phunkhang, P., Pierre, F., Priest, M., Rachupka, A., Raghuraman, S., Rameau, R., Ray, V., Raymond, C., Rege, F., Rise, C., Rogers, J., Rogov, P., Sahalie, J., Settipalli, S., Sharpe, T., Shea, T., Sheehan, M., Sherpa, N., Shi, J., Shih, D., Sloan, J., Smith, C., Sparrow, T., Stalker, J., Stange-Thomann, N., Stavropoulos, S., Stone, C., Stone, S., Sykes, S., Tchuinga, P., Tenzing, P., Tesfaye, S., Thoulutsang, D., Thoulutsang, Y., Topham, K., Topping, I., Tsamla, T., Vassiliev, H., Venkataraman, V., Vo, A., Wangchuk, T., Wangdi, T., Weiand, M., Wilkinson, J., Wilson, A., Yadav, S., Yang, S., Yang, X., Young, G., Yu, Q., Zainoun, J., Zembek, L., Zimmer, A., and Lander, E. S. (2005). Genome sequence, comparative analysis and haplotype structure of the domestic dog. Nature 438, 803-819. 
Michael, G., Xiao, L., Qi, X. Y., Dobrev, D., and Nattel, S. (2009). Remodelling of cardiac repolarization: how homeostatic responses can lead to arrhythmogenesis. Cardiovasc. Res. 81, 491-499.

Mutai, H., Kenyon, L. C., Locke, E., Kikuchi, N., and Oberholtzer, J. C. (2004). Characterization of the chicken inward rectifier $\mathrm{K}+$-channel IRK1/Kir2.1 gene. BMC Genomics 5, 90. doi:10.1186/1471-2164-5-90

Ojaimi, C., Qanud, K., Hintze, T. H., and Recchia, F. A. (2007). Altered expression of a limited number of genes contributes to cardiac decompensation during chronic ventricular tachypacing in dogs. Physiol. Genomics 29, 76-83.

Oros, A., Beekman, J. D., and Vos, M. A. (2008). The canine model with chronic, complete atrio-ventricular block. Pharmacol. Ther. 119, 168-178.

Priori, S. G., Pandit, S. V., Rivolta, I., Berenfeld, O., Ronchetti, E., Dhamoon, A., Napolitano, C., Anumonwo, J., Di Barletta, M. R., Gudapakkam, S., Bosi, G., StrambaBadiale, M., and Jalife, J. (2005). A novel form of short QT syndrome (SQT3) is caused by a mutation in the KCNJ2 gene. Circ. Res. 96, 800-807.

Redell, J. B., and Tempel, B. L. (1998). Multiple promoter elements interact to control transcription of the potassium channel gene, KCNJ2. J. Biol. Chem. 273, 22807-22818.

Roden, D. M. (1998). Taking the "idio" out of "idiosyncratic": predicting torsades de pointes. Pacing Clin. Electrophysiol. 21, 1029-1034.

Rodríguez-Menchaca, A. A., NavarroPolanco, R. A., Ferrer-Villada, T.,
Rupp, J., Sachse, F. B., TristaniFirouzi, M., and Sánchez-Chapula, J. A. (2008). The molecular basis of chloroquine block of the inward rectifier $\mathrm{K}_{\mathrm{IR}} 2.1$ channel. Proc. Natl. Acad. Sci. U.S.A. 105, 1364-1368.

Ryan, D. P., Da Silva, M. R., Soong, T. W., Fontaine, B., Donaldson, M. R., Kung, A. W., Jongjaroenprasert, W., Liang, M. C., Khoo, D. H., Cheah, J. S., Ho, S. C., Bernstein, H. S., Maciel, R. M., Brown, R. H. Jr., and Ptácek, L. J. (2010). Mutations in potassium channel Kir2.6 cause susceptibility to thyrotoxic hypokalemic periodic paralysis. Cell 140, 88-98.

Thomsen, M. B., Matz, J., Volders, P. G., and Vos, M. A. (2006a). Assessing the proarrhythmic potential of drugs: current status of models and surrogate parameters of torsades de pointes arrhythmias. Pharmacol. Ther. 112, 150-170.

Thomsen, M. B., Volders, P. G., Beekman, J. D., Matz, J., and Vos, M. A. (2006b). Beat-to-beat variability of repolarization determines proarrhythmic outcome in dogs susceptible to drug-induced torsades de pointes. J. Am. Coll. Cardiol. 48, 1268-1276.

Thomsen, M. B., Oros, A., Schoenmakers, M., Van Opstal, J. M., Maas, J. N., Beekman, J. D., and Vos, M. A. (2007). Proarrhythmic electrical remodelling is associated with increased beat-to-beat variability of repolarisation. Cardiovasc. Res. 73, 521-530.

Tian, B., Hu, J., Zhang, H., and Lutz, C. S. (2005). A large-scale analysis of mRNA polyadenylation of human and mouse genes. Nucleic Acids Res. 33, 201-212.

Tristani-Firouzi, M., and Etheridge, S. P. (2010). Kir 2.1 channelopathies: the
Andersen-Tawil syndrome. Pfluger Arch. 460, 289-294.

Vega, A. L., Tester, D. J., Ackerman, M. J., and Makielski, J. C. (2009). Protein kinase A-dependent biophysical phenotype for V227F-KCNJ2 mutation in catecholaminergic polymorphic ventricular tachycardia. Circ Arrhythm. Electrophysiol. 2, 540-547.

Xia, M., Jin, Q., Bendahhou, S., He, Y., Larroque, M. M., Chen, Y., Zhou, Q., Yang, Y., Liu, Y., Liu, B., Zhu, Q. Zhou, Y., Lin, J., Liang, B., Li, L., Dong, X., Pan, Z., Wang, R., Wan, H., Qiu, W., Xu, W., Eurlings, P., Barhanin, J., and Chen, Y. (2005). A Kir2.1 gain-of-function mutation underlies familial atrial fibrillation. Biochem. Biophys. Res. Commun. 332, 1012-1019.

Yan, D. H., Nishimura, K., Yoshida, K., Nakahira, K., Ehara, T., Igarashi, K., and Ishihara, K. (2005). Different intracellular polyamine concentrations underlie the difference in the inward rectifier $\mathrm{K}+$ currents in atria and ventricles of the guinea pig heart. J. Physiol. 563, 713-724.

Yang, B., Lin, H., Xiao, J., Lu, Y. Luo, X., Li, B., Zhang, Y., Xu, C., Bai, Y., Wang, H., Chen, G. and Wang, Z. (2007). The musclespecific microRNA miR-1 regulates cardiac arrhythmogenic potential by targeting GJA1 and KCNJ2. Nat. Med. 13, 486-491.

Zaritsky, J. J., Redell, J. B., Tempel, B. L., and Schwarz, T. L. (2001) The consequences of disrupting cardiac inwardly rectifying $\mathrm{K}+$ current (IK1) as revealed by the targeted deletion of the murine Kir2.1 and Kir2.2 genes. J. Physiol. 533, 697-710.

Zhao, J., Hyman, L., and Moore, C. (1999). Formation of mRNA $3^{\prime}$ ends in eukaryotes: mechanism, regulation, and interrelationships with other steps in mRNA synthesis. Microbiol. Mol. Biol. Rev. 63, 405-445.

Zobel, C., Cho, H. C., Nguyen, T. T., Pekhletski, R., Diaz, R. J., Wilson, G. J., and Backx, P. H. (2003). Molecular dissection of the inward rectifier potassium current $\left(\mathrm{I}_{\mathrm{K} 1}\right)$ in rabbit cardiomyocytes: evidence for heteromeric co-assembly of $\mathrm{K}_{\mathrm{ir} 2.1}$ and $\mathrm{K}_{\mathrm{ir2.2}}$. J. Physiol. 550, 365-372.

Conflict of Interest Statement: The authors declare that the research was conducted in the absence of any commercial or financial relationships that could be construed as a potential conflict of interest.

Received: 11 August 2011; accepted: 12 January 2012; published online: 30 January 2012

Citation: Houtman MJC, Takanari H, Kok BGJM, van Eck M, Montagne DR Vos MA, de Boer TP and van der Heyden MAG (2012) Experimental mapping of the canine KCNJ2 and KCNJ12 gene structures and functional analysis of the canine $K_{I R} 2.2$ ion channel. Front. Physio. 3:9. doi: 10.3389/fphys.2012.00009

This article was submitted to Frontiers in Cardiac Electrophysiology, a specialty of Frontiers in Physiology.

Copyright (C) 2012 Houtman, Takanari, Kok, van Eck, Montagne, Vos, de Boer and van der Heyden. This is an openaccess article distributed under the terms of the Creative Commons Attribution Non Commercial License, which permits non-commercial use, distribution, and reproduction in other forums, provided the original authors and source are credited. 